\title{
Analyzing the Electrooxidation of Ethylene Glycol and Glucose Over Platinum- Modified Gold Electrocatalysts in Alkaline Electrolyte Using in-situ Infrared Spectroscopy
}

Elizabeth G. Mahoney ${ }^{\mathrm{a}}$, Wenchao Sheng ${ }^{\mathrm{b}}$, Mei Cheng ${ }^{\mathrm{b}}$, Kevin X. Lee ${ }^{\mathrm{b}}$, Yushan Yan ${ }^{\mathrm{a}}$, Jingguang G. Chen ${ }^{\mathrm{b} *}$

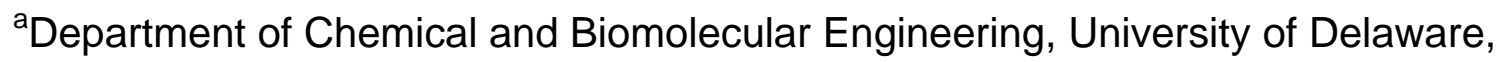
Newark, DE 19716

${ }^{\mathrm{b}}$ Department of Chemical Engineering, Columbia University, New York, NY 10027

* Corresponding author: Dr. Jingguang G. Chen: Tel.: +1 212-854-6166, Fax: +1 212854-3054, E-mail: jgchen@columbia.edu 


\begin{abstract}
Platinum modified gold $(\mathrm{Pt} / \mathrm{Au})$ catalysts are evaluated for the electrooxidation of ethylene glycol (EG) and glucose (Glc). The Pt/Au catalysts are synthesized on an Au disk and supported $\mathrm{Au} / \mathrm{C}$ particles through the galvanic displacement of a copper monolayer with $\mathrm{Pt}$. The $\mathrm{Pt} / \mathrm{Au}$ catalysts are compared to monometallic $\mathrm{Pt}$ and $\mathrm{Au}$ catalysts for the oxidation of EG and Glc in alkaline electrolyte. The Pt/Au disk has an onset potential for these reactions that is similar to $\mathrm{Pt}$ and is lower than $\mathrm{Au}$. The supported catalysts are less active toward the electrooxidation of EG and Glc than the corresponding disk electrodes, but the $\mathrm{Pt} / \mathrm{Au} / \mathrm{C}$ also has an onset potential similar to $\mathrm{Pt} / \mathrm{C}$. In-situ FTIR is used to analyze the $\mathrm{C}-\mathrm{C}$ bond scission in both reactions on the surfaces of $\mathrm{Pt}, \mathrm{Au}$, and $\mathrm{Pt} / \mathrm{Au}$ disks. While the Pt/Au disk is found to have a low onset potential for the oxidation of $\mathrm{EG}$, it does not produce as much $\mathrm{CO}_{2}$ as bulk Pt. On the other hand, the FTIR results show that $\mathrm{CO}_{2}$ is produced for the oxidation of Glc on the $\mathrm{Pt} / \mathrm{Au}$ disk. These results show promise for the possibility of decreasing the amount of Pt needed for the electrooxidation of polyol molecules.
\end{abstract}

Keywords: Electrooxidation, Alkaline, Pt, Au, Ethylene glycol, Glucose 


\section{Introduction}

Fuel cells have been developed as a possible alternative energy conversion device that achieves high efficiencies. In addition, they also provide the benefit of having flexible fuel options that can be tailored to fit a specific need. Among many possible feedstock options, hydrogen has been the most studied over the past several decades, but presents concerns associated with its storage and the fact that $\mathrm{CO}_{2}$ is generated as byproduct in most $\mathrm{H}_{2}$ production routes. However, other feedstock options, particularly oxygen-containing hydrocarbons (i.e., oxygenates), may be more commercially viable due to their compatibility with the existing chemical infrastructure for storage and transportation. Two oxygenates that show potential as replacements for hydrogen as a feedstock for fuel cells are ethylene glycol (EG) and glucose (Glc). EG as a fuel cell feedstock is advantageous because it can be produced from non-food competing biomass sources using inexpensive nickel-based catalysts, rendering the fuel potentially $\mathrm{CO}_{2}$-neutral.[1-3] Being one of the simplest oxygenates derived from biomass, it has also been used as a probe molecule to estimate the catalytic behavior for more complicated oxygenates such as Glc, which has the same 1:1 carbon to oxygen ratio as EG.[4,5] Glc is easily produced in nature via photosynthesis in plants and is considered a waste product in many processes, which makes it a promising candidate for a $\mathrm{CO}_{2}$-neutral fuel.[6]

Despite the advantages of using EG or Glc as a fuel cell feedstock, the development of commercially viable fuel cells has also been hindered by the prohibitive cost and scarcity of platinum (Pt) electrocatalysts. Although the ideal electrocatalysts for ethylene glycol oxidation (EGO) and glucose oxidation (GlcO) in alkaline media are Pt- 
and palladium (Pd)-based electrocatalysts, which are too expensive for widespread applications,[3,7] using a Pt-modified electrocatalyst with very low Pt loadings would reduce the cost of the fuel cell. Pt or Pd-modified electrocatalysts have been previously used to minimize the expense of the catalysts for the oxygen reduction reaction (ORR)[8-10], hydrogen evolution reaction (HER)[11-13] in acidic electrolytes, as well

as ethanol oxidation in alkaline media. $[14,15]$ In this study, we report the evaluation of the activity of Pt-modified gold $(\mathrm{Pt} / \mathrm{Au})$ disk and supported $(\mathrm{Pt} / \mathrm{Au} / \mathrm{C})$ electrodes for EGO and GlcO. To synthesize the Pt/Au catalysts, a coverage equivalent to a monolayer of Pt was deposited on Au substrates via the galvanic displacement of a copper monolayer. The EGO and GlcO activity in $0.1 \mathrm{M} \mathrm{KOH}$ was obtained on $\mathrm{Pt}, \mathrm{Au}$, and $\mathrm{Pt} / \mathrm{Au}$ disk electrodes, as well as on the corresponding supported catalysts $\mathrm{Pt} / \mathrm{C}, \mathrm{Au} / \mathrm{C}$, and $\mathrm{Pt} / \mathrm{Au} / \mathrm{C}$ because of the practical application of supported catalysts in fuel cell devices. Furthermore, in-situ FTIR was performed on each disk electrode to gain further insight into the formation of $\mathrm{CO}_{2}$ from the electrooxidation of $\mathrm{EGO}$ and $\mathrm{GlcO}$.

\section{Experimental}

\subsection{Electrode preparation}

The Pt and Au disk electrodes used for this study are $5 \mathrm{~mm}$ in diameter. Prior to electrochemical testing, the Pt and Au disks were polished to a mirror finish using 0.05 $\mu \mathrm{m}$ alumina powder. Each was then rinsed with deionized water and dried with air before testing. Supported catalyst thin film electrodes were prepared by dropping catalyst inks onto clean glassy carbon disk electrodes of $5 \mathrm{~mm}$ in diameter. A $46 \mathrm{wt} \%$ 
$\mathrm{Pt} / \mathrm{C}$ (Tanaka Kikinzoku International Inc.) ink with a solid loading of $\sim 0.15 \mathrm{mg} \mathrm{mL}^{-1}$ was prepared by dispersing the catalyst in deionized water via sonication.[16] The Pt/C electrodes were made by depositing a $20 \mu \mathrm{L}$ drop of ink on a glassy carbon electrode, resulting in a loading of $\sim 7 \mu \mathrm{g}_{\mathrm{Pt}} \mathrm{cm}^{-2}$ disk. A $40 \mathrm{wt} \% \mathrm{Au} / \mathrm{C}$ (Premetek) ink with a solid loading of $\sim 1.6 \mathrm{mg} \mathrm{mL}^{-1}$ was prepared by dispersing the catalyst in a solution of $50 \%$ isopropanol and $50 \%$ deionized water via sonication. The $\mathrm{Au} / \mathrm{C}$ electrodes were made by depositing a $10 \mu \mathrm{L}$ drop of ink on a glassy carbon electrode, resulting in a loading of

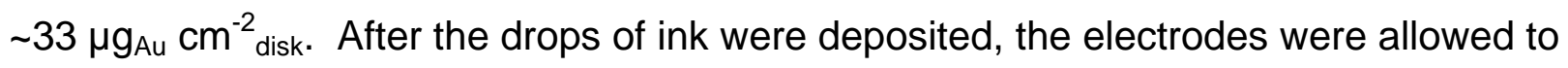
dry overnight in air.

\subsection{Electrochemical measurements}

All electrochemical syntheses and measurements were performed using a glass three-electrode cell and a Princeton Applied Research VersaSTAT 4 potentiostat at room temperature. A double junction saturated $\mathrm{Ag} / \mathrm{AgCl}$ electrode was used as the reference and a coiled Pt wire was used as the counter electrode. All electrolytes used were purged with Ar. Unless explicitly stated, all potentials reported are referenced to the reversible hydrogen electrode (RHE), which was calibrated by performing hydrogen oxidation/evolution experiments on a Pt disk electrode in $0.1 \mathrm{M} \mathrm{KOH}$.

\subsubsection{Pt-modified Au electrode synthesis}

Pt is deposited on Au substrates in monolayer-equivalent quantities through the galvanic displacement of a Cu monolayer, a procedure that is well established in the literature.[17,18] This method was used to synthesize both the Pt/Au disk and Pt/Au/C 
electrodes. The Au disk or Au/C electrode was submerged in a solution of $0.05 \mathrm{M}$ $\mathrm{CuSO}_{4}$ and $0.05 \mathrm{M} \mathrm{H}_{2} \mathrm{SO}_{4}$. A double-junction $\mathrm{Ag} / \mathrm{AgCl}$ electrode and a coiled Pt wire were used as the reference and counter electrode, respectively. The potential was cycled from $0.15 \mathrm{~V}$ to $0.6 \mathrm{~V}$ vs. $\mathrm{Ag} / \mathrm{AgCl}$ and the working electrode was removed at 0.15 V vs. $\mathrm{Ag} / \mathrm{AgCl}$ to deposit a monolayer of $\mathrm{Cu}$ on the $\mathrm{Au}$. The electrode was immediately rinsed in deionized water and transferred to a solution of $0.001 \mathrm{M} \mathrm{K}_{2} \mathrm{PtCl}_{4}$ in $0.05 \mathrm{M}$ $\mathrm{H}_{2} \mathrm{SO}_{4}$ for at least two minutes to ensure the complete galvanic displacement of $\mathrm{Cu}$ by $\mathrm{Pt}$. The Pt/Au disks and Pt/Au/C electrodes were rinsed and evaluated immediately after synthesis.

\subsubsection{Electrooxidation measurements}

Before performing EGO or GlcO measurements, the electrodes were cycled in $0.1 \mathrm{M} \mathrm{KOH}$ to obtain background cyclic voltammograms (CVs). EG or Glc was added to the $0.1 \mathrm{M} \mathrm{KOH}$ to bring the solution to a concentration of $1 \mathrm{M} \mathrm{EG}$ or $0.1 \mathrm{M}$ Glc before the oxidation CVs were conducted. Chronoamperometry (CA) was also completed under the same conditions. The system was allowed to equilibrate for 3 seconds at the chosen potential before data points were collected.

\subsection{In-situ FTIR measurements}

FTIR spectroscopy measurements were conducted with a Nicolet Nexus 870 spectrometer similar to previous studies.[19] The spectrometer is equipped with a liquid nitrogen-cooled MCT detector. The electrochemical cell consists of a ZnSe hemisphere window and an electrochemical cell with three electrodes (working electrode, $\mathrm{Ag} / \mathrm{AgCl}$ 
as reference electrode, and Pt coil as counter electrode). The electrolyte is $0.1 \mathrm{M}$ of $\mathrm{KOH}$. The IR chamber was purged with $\mathrm{N}_{2}$ for approximately 3 hours to remove any possible signal interference from $\mathrm{CO}_{2}$ and water moisture. The absorbance spectra were calculated as the ratio $\log \left(S_{S} / S_{R}\right)$, where $S_{S}$ is the absorbing species and $S_{R}$ is the corresponding reference. The first spectrum was taken as the reference and all the other spectra were taken at different applied potentials at a scan rate of $1 \mathrm{mV} / \mathrm{s}$. All potentials were converted to the RHE scale using the same calibration as the oxidation CVs. Positive FTIR bands correspond to the formation of products while negative bands represent the consumption of reactants.

\section{Results and Discussion}

\subsection{Characterization of Pt/Au catalysts}

Detailed characterization of the $\mathrm{Pt} / \mathrm{Au}$ disk and $\mathrm{Pt} / \mathrm{Au} / \mathrm{C}$ electrodes was reported in a recent publication.[20] Using transmission electron microscopy (TEM), the diameters of the Pt and Au particles used for the supported catalysts were found to be $2.5 \pm 0.6 \mathrm{~nm}$ and $14 \pm 6.9 \mathrm{~nm}$, respectively, based on averaging 200 particles. The relatively large size of the $\mathrm{Au}$ particles suggests that $\mathrm{Au} / \mathrm{C}$ may exhibit similar properties to the Au disk.

To confirm the presence of $\mathrm{Pt}$ on the surface of $\mathrm{Au}$, the CVs of $\mathrm{Au}, \mathrm{Pt}$, and $\mathrm{Pt} / \mathrm{Au}$ disk electrodes were compared (Fig. 1a). The Au CV shows a hydroxyl adsorption peak at $1.2 \mathrm{~V}$, but does not show hydrogen adsorption/desorption that is typical on $\mathrm{Pt}$ surfaces.[21,22] The Pt CV shows features characteristic of the hydrogen 
underpotential deposition (H-UPD) region on $\mathrm{Pt}(110)$ and $\mathrm{Pt}(100)$ at $0.3 \mathrm{~V}$ and $0.4 \mathrm{~V}$, respectively, followed by the onset of the hydroxyl adsorption at above 0.6 V.[23] The presence of bulk Pt features in the $\mathrm{CV}$ of the Pt/Au disk confirms the presence of Pt on the Au substrate. The same trends follow for the $\mathrm{Au} / \mathrm{C}, \mathrm{Pt} / \mathrm{C}$, and $\mathrm{Pt} / \mathrm{Au} / \mathrm{C}$ supported electrodes (Fig. 1b).

In the $\mathrm{CVs}$ for both the $\mathrm{Pt} / \mathrm{Au}$ disk and $\mathrm{Pt} / \mathrm{Au} / \mathrm{C}$, the formation and reduction of $\mathrm{Au}$ oxides are visible, indicating that there is not a full coverage of Pt on the Au disk. Since Pt forms small nanoislands on the Au surface instead of a fully developed epitaxial monolayer,[20,24] some amount of Au substrate is expected to be left uncovered. However, the $\mathrm{AuO}$ reduction peak in the $\mathrm{Pt} / \mathrm{Au} / \mathrm{C} \mathrm{CV}$ is much smaller than the $\mathrm{AuO}$ reduction peak in the $\mathrm{Pt} / \mathrm{Au}$ disk $\mathrm{CV}$, suggesting that the coverage of $\mathrm{Pt}$ is higher for Pt/Au/C than the Pt/Au disk.

The electrochemically active surface area (ECSA) of the Au disk was calculated by integrating the area of the peak corresponding to the reduction of $\mathrm{AuO}$ at approximately $1.05 \mathrm{~V}$ vs. RHE, which corresponds to a charge density of $390 \mu \mathrm{C} \mathrm{cm}^{-}$ ${ }^{2}$.[25] The upper potential limit for these CVs was determined by using the potential corresponding to the minimum current before the oxygen evolution reaction.[26,27] Since this minimum is difficult to determine for $\mathrm{Au} / \mathrm{C}$ and $\mathrm{Pt} / \mathrm{Au} / \mathrm{C}$, the same potential was used for the disks and supported samples. The ECSAs of the Pt and Pt/Au samples were found by $\mathrm{CO}$ stripping in $0.1 \mathrm{M} \mathrm{KOH}$.[20] The experimental details can be found in Ref. 20. The ECSAs were used to normalize the respective electrooxidation currents during EGO and GlcO. The ECSAs were also divided by the geometric area of the electrode, yielding a roughness factor for each electrode (Table 1). The 
roughness factors of $\mathrm{Pt} / \mathrm{Au}$ and $\mathrm{Pt} / \mathrm{Au} / \mathrm{C}$ samples are approximately equivalent to that of the pure Au substrate.

\subsection{Ethylene glycol oxidation activity on Au, Pt, and Pt/Au catalysts}

The activity of the Pt/Au catalysts was tested for EGO in alkaline electrolytes and compared to the activity of monometallic Pt and Au catalysts for both disk and supported electrodes (Fig. 2). All surfaces show two anodic peaks in the forward and reverse scans of each CV. In the forward scan, the oxidation current precipitously decreases due to the formation of surface oxides that render the surface inactive. For both $\mathrm{Pt}$ and $\mathrm{Pt} / \mathrm{Au}$ catalysts, the maximum current density is reached at $\sim 1.2 \mathrm{~V}$. For the Au catalysts, the maximum occurs at $\sim 1.5 \mathrm{~V}$. In the reverse scan, the surface oxides are reduced and the oxidation current increases again. Both Pt and Au catalysts yield a higher oxidation current density in alkaline conditions over acidic conditions (data not shown), consistent with results previously reported.[28-30]

The onset potential of oxidation on the Pt disk is approximately $0.2 \mathrm{~V}$ lower than that of the Au disk. While maintaining an onset potential similar to that of the Pt disk, the Pt/Au disk achieves a higher maximum current than the Pt disk. Supported Pt/C and $\mathrm{Pt} / \mathrm{Au} / \mathrm{C}$ produce less current than their respective disk electrodes (Fig $2 b$ ), but follow the same trends. Compared to $\mathrm{Pt} / \mathrm{C}, \mathrm{Au} / \mathrm{C}$ has an onset potential $0.2 \mathrm{~V}$ higher than $\mathrm{Pt} / \mathrm{C}$, but also achieves a higher maximum current. The Pt/Au disk and $\mathrm{Pt} / \mathrm{Au} / \mathrm{C}$ electrodes have a small shoulder at $1.4 \mathrm{~V}$ that corresponds to $\mathrm{Au} / \mathrm{C}$, indicating that there is uncovered Au participating in the reaction. 
Chronoamperometry $(\mathrm{CA})$ measurements were performed to evaluate the steady-state activity and stability of each disk electrode for the oxidation of EG at $0.8 \mathrm{~V}$ vs. RHE (Fig. 3). Au is essentially inactive at this potential. The Pt and Pt/Au disks initially yield a current density of $8 \mathrm{~mA} \mathrm{~cm}^{-2} \mathrm{Pt}$ and $6 \mathrm{~mA} \mathrm{~cm}^{-2}$, respectively, but $\mathrm{Pt}$ rapidly deactivates to a steady-state current of $\sim 0.3 \mathrm{~mA} \mathrm{~cm}^{-2} \mathrm{Pt}$. Pt/Au, however, retains a current of $\sim 4.25 \mathrm{~mA} \mathrm{~cm}^{-2} \mathrm{Pt}$ until 3600 seconds.

To study the stability of the Pt/Au catalyst for EGO, the Pt/Au disk was further characterized with X-ray photoelectron spectroscopy (XPS). As shown in Fig. 4, the detection of the Pt $4 \mathrm{f}$ features indicates the presence of Pt on the Au surface. In addition to metallic $\mathrm{Pt}$, which is characterized by peaks at approximately 74 and $71 \mathrm{eV}$, peaks at $\sim 78$ and $75 \mathrm{eV}$ indicate the presence of $\mathrm{Pt}^{4+}$ on the surface. This has been attributed to the hypothesis that the galvanic displacement of $\mathrm{Cu}$ with Pt does not form an entirely reduced Pt overlayer on Au substrates for Pt overlayers under 2 monolayers in thickness.[31] Although $\mathrm{Pt}^{2+}$ may also be present, no peaks distinct from $\mathrm{Pt}^{0}$ or $^{\mathrm{Pt}^{4+}}$ can be clearly observed in Fig. 4. The XPS spectrum does not change appreciably after the EGO CA at $0.8 \mathrm{~V}$ vs. RHE, indicating that the Pt/Au surface is relatively stable at reaction potentials for EGO.

While the $\mathrm{CV}$ and $\mathrm{CA}$ results can show general trends for each electrode, information regarding the EGO mechanism is difficult to obtain from these methods alone. The mechanism of EGO on Pt and Au catalysts in alkaline media has been well studied,[32] but how the mechanism changes on the Pt/Au surface is unclear. Therefore, FTIR was used to analyze the EGO intermediates and products on the $\mathrm{Pt}$, $\mathrm{Au}$, and Pt/Au disks (Fig 5) using known vibrational peak assignments (Table 2). 
The FTIR spectra for EGO on the Au disk agrees with previous spectra obtained in $0.5 \mathrm{M} \mathrm{KOH}$ (Fig 5a).[32] Vibrational features appear at around $\sim 1.0 \mathrm{~V}$, similar to the onset potential observed in the Au disk EGO CV (Fig 3a). The peaks at 1577, 1409, 1323,1237 , and $1074 \mathrm{~cm}^{-1}$ indicate that glyoxal and glycolate are present after the onset of oxidation at $\sim 1.0 \mathrm{~V}$. A peak at $1353 \mathrm{~cm}^{-1}$ appears at $1.3 \mathrm{~V}$, suggesting the formation of formate. This formate species may come from the oxidation of glycolate at higher potentials.[33] The lack of a peak at $2341 \mathrm{~cm}^{-1}$ indicates that very little $\mathrm{CO}_{2}$ is produced on the Au surface. It is well established that Au electrocatalysts in alkaline media do not break the $\mathrm{C}-\mathrm{C}$ bond and instead provides a hydroxylated surface on which a deprotonated alcohol may react.[30]

Conversely, the Pt surface is able to break the $\mathrm{C}-\mathrm{C}$ bond in EG at high overpotentials, as evident by the onset of the $\mathrm{CO}_{2}$ band at $2341 \mathrm{~cm}^{-1}$ at $1.3 \mathrm{~V}$ (Fig $5 \mathrm{~b}$ ). At $0.7 \mathrm{~V}$, small vibrational peaks appear, which by $0.9 \mathrm{~V}$ have developed into peaks at $1577,1409,1323,1237$, and $1074 \mathrm{~cm}^{-1}$, corresponding to the characteristic vibrational frequencies of of glyoxal, glycolate, and oxalate. The small shoulder at $1307 \mathrm{~cm}^{-1}$ also suggests that oxalate is produced.

The Pt/Au disk spectra show a weak $\mathrm{CO}_{2}$ peak at $2341 \mathrm{~cm}^{-1}$ by $1.3 \mathrm{~V}$ (Fig. $5 \mathrm{c}$ ), but it is not as prominent as that of the Pt surface. The peak at $1577 \mathrm{~cm}^{-1}$ associated with glyoxal and glycolate is broadened in the Pt/Au spectra. Otherwise, the IR features at $1577,1409,1323,1237$, and $1074 \mathrm{~cm}^{-1}$ on the Pt/Au surface are similar to $\mathrm{Au}$, indicating that the main products on the Pt-modified surface are glyoxal and glycolate.

While the Pt/Au surface does decrease the onset potential of the EGO reaction compared to pure Au, which is important for fuel cell applications, the FTIR results 
indicate that the $\mathrm{Pt} / \mathrm{Au}$ surface does not oxidize $\mathrm{EG}$ completely to $\mathrm{CO}_{2}$ as efficiently as Pt. While this decreases the overall Faradaic efficiency for the Pt/Au surface, it increases the stability of the catalyst (Fig. 4). One possible explanation is that since the $\mathrm{Pt} / \mathrm{Au}$ does not break the C-C bond, no carbon residues are produced to poison the catalyst surface.

\subsection{Glucose oxidation activity on $\mathrm{Au}, \mathrm{Pt}$, and Pt/Au}

The activities of $\mathrm{Pt} / \mathrm{Au}$ catalysts were tested for $\mathrm{GlcO}$ under alkaline conditions and compared to Pt and Au (Fig. 6). The Au disk and supported Au/C for GlcO have onset potentials of $0.3 \mathrm{~V}$ vs. RHE, which are much lower than those of the Au catalysts for EGO. In addition, even at low potentials, the Au disk and Au/C achieve a higher current density than the Pt catalysts for GlcO. During the forward scan, the Au disk attains a current density of about $8 \mathrm{~mA} \mathrm{~cm}^{-2}$ Au at $0.75 \mathrm{~V}$ vs. RHE. The oxidation current subsides at 1.6 V, which coincides with the formation of oxides on the Au surface.[20] In the reverse scan, after the Au surface is reduced, there is a sharp increase in oxidation current, suggesting that the oxidized Au surface does not participate in GlcO.[34] The supported Au/C electrode for $\mathrm{GlcO}$ also has an onset potential at $0.3 \mathrm{~V}$ and reaches approximately the same current density as the Au disk, but there are two oxidation peaks in the forward scan at $\sim 0.8 \mathrm{~V}$ and $1.5 \mathrm{~V}$. This is likely due to the presence of different Au facets on the Au particles to the Au disk.[35] The reverse oxidation peak of the $\mathrm{Au} / \mathrm{C} \mathrm{CV}$ for $\mathrm{GlcO}$ is not as pronounced as the Au disk.

In agreement with literature on $\mathrm{GlcO}$, the Pt disk $\mathrm{CV}$ has three oxidation peaks in the forward scan, appearing at $0.3 \mathrm{~V}, 0.75 \mathrm{~V}$, and $1.1 \mathrm{~V}$, and three smaller oxidation 
peaks in the reverse scan.[36-38] The first peak has been attributed to the dehydration and adsorption of Glc onto the Pt surface, the second to oxidation of adsorbed Glc by the $\mathrm{OH}_{\mathrm{ad}}$ species, and the third is possibly related to the oxidation of carbon containing residues left on the Pt surface.[38-41] The reverse scan peaks occur at similar potentials as the forward scan peaks. While Pt has a lower onset potential than Au with oxidation commencing at slightly above $0 \mathrm{~V}$ vs. RHE, the Pt electrode achieves a lower peak current density, with the highest current being $4 \mathrm{~mA} \mathrm{~cm}^{-2}{ }_{\mathrm{Pt}}$ at $1.2 \mathrm{~V}$ vs. RHE. The $\mathrm{Pt} / \mathrm{C}$ GlcO CV is similar to the Pt disk GlcO CV, but with two differences (Fig 6b). First, $\mathrm{Pt} / \mathrm{C}$ achieves approximately half the current density as the Pt disk. Second, the ratio between the forward oxidation peaks is different between supported $\mathrm{Pt} / \mathrm{C}$ and the $\mathrm{Pt}$ disk. Specifically, the last oxidation peak for $\mathrm{Pt} / \mathrm{C}$ is about equal in magnitude to the first peak, while on the Pt disk it is about twice as large. This difference can also be attributed to the presence of different Pt facets on the particles compared to the disk.[41]

Both Pt/Au catalysts have a slightly lower onset potential for GlcO than their respective Au substrates. In the case of $\mathrm{Pt} / \mathrm{Au} / \mathrm{C}$ for $\mathrm{GlcO}$, the onset potential matches that of $\mathrm{Pt} / \mathrm{C}$. However, unlike for EGO, the $\mathrm{Pt} / \mathrm{Au}$ disk and $\mathrm{Pt} / \mathrm{Au} / \mathrm{C}$ oxidation $\mathrm{CVs}$ for $\mathrm{GlcO}$ are more similar to the $\mathrm{Au}$ and $\mathrm{Au} / \mathrm{C}$ catalysts.

The steady-state activity and stability of the $\mathrm{Pt}, \mathrm{Au}$, and $\mathrm{Pt} / \mathrm{Au}$ disks for GlcO were compared by CA measurements at $0.4 \mathrm{~V}$ vs. RHE (Fig 7). Similar to the EGO CA experiments, Pt/Au was found to be more active and more stable than Pt at the chosen potential, though the difference is relatively small. In the case of $\mathrm{GlcO}, \mathrm{Au}$ is more active than Pt at $0.4 \mathrm{~V}$ vs. RHE. 
To elucidate the $\mathrm{GlcO}$ reaction pathways occurring on $\mathrm{Au}, \mathrm{Pt}$, and $\mathrm{Pt} / \mathrm{Au}$, in-situ FTIR was used on each disk surface during the GlcO reaction (Fig 8) and compared to known peak assignments (Table 3). On the Au surface (Fig 8a), a broad peak is evident at $1639 \mathrm{~cm}^{-1}$ from $0.3 \mathrm{~V}$ onward. At $0.5 \mathrm{~V}$, a small shoulder appears that corresponds to gluconate at $1595 \mathrm{~cm}^{-1}$, which is also represented by the peak at 1043 $\mathrm{cm}^{-1}$. By $0.9 \mathrm{~V}$, this gluconate shoulder is mostly overtaken by the large peak at 1639 $\mathrm{cm}^{-1}$. The consumption of Glc is indicated by the negative-going peaks at 1388 and $1177 \mathrm{~cm}^{-1}$ starting at $0.5 \mathrm{~V}$. Also at $0.7 \mathrm{~V}$, a shoulder appears at about $1740 \mathrm{~cm}^{-1}$ along with the peaks at 1226,1191 , and $1056 \mathrm{~cm}^{-1}$, indicating that gluconolactone is formed. The Au surface produces a small amount of $\mathrm{CO}_{2}$, as evidenced by the relatively weak peak at $2341 \mathrm{~cm}^{-1}$. Previous studies confirm that in $0.1 \mathrm{M} \mathrm{NaOH}$, the Au surface produces a significant amount of gluconate as a final oxidation product.[36]

The Pt disk spectra differ from those of the Au disk. At the beginning of the scan, broad positive-going peaks at $1639 \mathrm{~cm}^{-1}$ and $1039 \mathrm{~cm}^{-1}$ are apparent, though they are not as dominant as in the Au scan, along with negative going peaks at 1388 and 1177 $\mathrm{cm}^{-1}$ indicating the consumption of Glc. The $\mathrm{CO}_{2}$ peak at $2341 \mathrm{~cm}^{-1}$ starts to appear at approximately $0.5 \mathrm{~V}$. By $0.9 \mathrm{~V}$, and peaks at $1740,1226,1191,1126$ and $1056 \mathrm{~cm}^{-1}$ start to form, indicating the production of gluconolactone.

It is interesting to note that the broad peak at $1639 \mathrm{~cm}^{-1}$ is absent from the spectra of the $\mathrm{Pt} / \mathrm{Au}$ disk. There is a peak located at $1593 \mathrm{~cm}^{-1}$, which is more consistent with the formation of gluconate. The production of gluconate is also confirmed by the peak at $1043 \mathrm{~cm}^{-1}$. Production of gluconolactone starts at about $1.3 \mathrm{~V}$ with the appearance of vibrational features at 1740, 1226, and $1191 \mathrm{~cm}^{-1}$. 
For the Pt and Au disks, the peak at $1639 \mathrm{~cm}^{-1}$ is dominant in the spectra over all potentials, but is not associated with glucose or any of the expected oxidation products. It was observed in the spectra of $\mathrm{Pt}$ in $\mathrm{NaOH}$ for GlcO in a previous study, but was not assigned.[42] This may be due to the adsorption of ring-opened glucose on the Pt and Au disks. While $\beta-D-$ glucose is known to be the most reactive species in solution for GlcO, there still may be an adsorption of ring-opened glucose that occurs at all potentials, leading to the large feature at $1639 \mathrm{~cm}^{-1}$ on $\mathrm{Pt}$ and $\mathrm{Au}$. The Pt/Au surface does not show this peak, suggesting that the nature of the adsorbed species is different from that on $\mathrm{Pt}$ and $\mathrm{Au}$, and that the $\mathrm{Pt} / \mathrm{Au}$ surface selectively binds the reactive $\beta-\mathrm{D}-$ glucose species.

Overall, the pathways of $\mathrm{GlcO}$ on the $\mathrm{Pt}, \mathrm{Au}$, and $\mathrm{Pt} / \mathrm{Au}$ disks follow the mechanism that is outlined in literature on metal surfaces.[34,36-38,42] First, the glucose adsorbs on the surface by reacting with solution phase $\mathrm{OH}^{-}$, forming a dehydrogenated molecule. This molecule can be oxidized directly to gluconate, which is observed in the IR spectra at all potentials. Alternatively, the adsorbed glucose can also be oxidized to gluconolactone, which reacts in alkaline solutions to form gluconate. While $\mathrm{CO}_{2}$ is produced, it is not the main product. The production of $\mathrm{CO}_{2}$ likely occurs from the further oxidation of gluconate and gluconolactone.

While the Pt/Au disk electrode has a mechanism similar to the Au disk for EGO, in the GlcO reaction the Pt/Au disk more closely resembles that of the Pt disk. This makes $\mathrm{Pt} / \mathrm{Au}$ catalysts promising candidates for polyol oxidation while retaining a low $\mathrm{Pt}$ loading. While $A u$ is an expensive support, the results demonstrate the proof-ofprinciple of using an equivalent of monolayer coverage of Pt to approach Pt-like 
properties, suggesting that modifying other, less expensive substrates with Pt may also be plausible.

Although one of the objectives of the current study is to use EG as a probe molecule for Glc, the results show that there are differences in activity and electrooxidation mechanism for EGO and GlcO. For example, Pt/Au does not break the $\mathrm{C}-\mathrm{C}$ bond in EGO and consequently shows a higher catalytic stability than Pt or Au. In contrast, $\mathrm{Pt} / \mathrm{Au}$ does break the $\mathrm{C}-\mathrm{C}$ bond for $\mathrm{GlcO}$, but deactivates quickly likely from carbon deposition. Further studies are needed to identify reaction intermediates and pathways that lead to these differences.

\section{Conclusions}

The Au disk and supported Au/C particles were modified with Pt via the galvanic displacement of an underpotentially deposited monolayer of copper. These bimetallic samples were compared to monometallic $\mathrm{Pt}$ and Au catalysts for the electrocatalysis of $\mathrm{EGO}$ and $\mathrm{GlcO}$ in alkaline electrolyte. For EGO the Pt/Au disk electrode and $\mathrm{Pt} / \mathrm{Au} / \mathrm{C}$ have a similar onset potential as the $\mathrm{Pt}$ disk and $\mathrm{Pt} / \mathrm{C}$, respectively. $\mathrm{Pt} / \mathrm{Au}$ catalysts are more stable for EGO than either Pt or Au. Using in-situ FTIR, it was confirmed that $\mathrm{Pt} / \mathrm{Au}$ does not break the $\mathrm{C}-\mathrm{C}$ bond in $\mathrm{EG}$. For $\mathrm{GlcO}$, the Pt/Au surface shows behavior

similar to Au and provides a current density that is slightly higher than Pt. Both Pt and $\mathrm{Pt} / \mathrm{Au}$ are active for breaking the $\mathrm{C}-\mathrm{C}$ bond in $\mathrm{Glc}$, as indicated by the presence of $\mathrm{CO}_{2}$ in the FTIR spectra.

\section{Acknowledgements:}


This work is supported by the US Department of Energy (DE-FG02-13ER16381). EGM acknowledges the US National Science Foundation for an NSF Graduate Fellowship.

\section{References}

[1] N. Ji, M. Zheng, A. Wang, T. Zhang, J.G. Chen, Nickel-promoted tungsten carbide catalysts for cellulose conversion: effect of preparation methods., ChemSusChem. 5 (2012) 939-44. doi:10.1002/cssc.201100575.

[2] R.B. de Lima, V. Paganin, T. Iwasita, W. Vielstich, On the electrocatalysis of ethylene glycol oxidation, Electrochim. Acta. 49 (2003) 85-91. doi:10.1016/j.electacta.2003.05.004.

[3] H. Yue, Y. Zhao, X. Ma, J. Gong, Ethylene glycol: properties, synthesis, and applications., Chem. Soc. Rev. 41 (2012) 4218-44. doi:10.1039/c2cs15359a.

[4] M. Salciccioli, W. Yu, M. a Barteau, J.G. Chen, D.G. Vlachos, Differentiation of O$\mathrm{H}$ and $\mathrm{C}-\mathrm{H}$ bond scission mechanisms of ethylene glycol on Pt and Ni/Pt using theory and isotopic labeling experiments., J. Am. Chem. Soc. 133 (2011) 79968004. doi:10.1021/ja201801t.

[5] A.L. Stottlemyer, H. Ren, J.G. Chen, Reactions of methanol and ethylene glycol on Ni/Pt: Bridging the materials gap between single crystal and polycrystalline bimetallic surfaces, Surf. Sci. 603 (2009) 2630-2638. doi:10.1016/j.susc.2009.06.016.

[6] A. Brouzgou, L.L. Yan, S.Q. Song, P. Tsiakaras, Glucose electrooxidation over $\mathrm{PdxRh/C}$ electrocatalysts in alkaline medium, Appl. Catal. B Environ. 147 (2014) 481-489. doi:10.1016/j.apcatb.2013.09.024.

[7] H.J. Kim, S.M. Choi, S. Green, G. a. Tompsett, S.H. Lee, G.W. Huber, et al., Highly active and stable PtRuSn/C catalyst for electrooxidations of ethylene glycol and glycerol, Appl. Catal. B Environ. 101 (2011) 366-375. doi:10.1016/j.apcatb.2010.10.005.

[8] J. Zhang, M.B. Vukmirovic, K. Sasaki, A.U. Nilekar, M. Mavrikakis, R.R. Adzic, Mixed-Metal Pt Monolayer Electrocatalysts for Enhanced Oxygen Reduction Kinetics, (2005) 12480-12481.

[9] K. Sasaki, J.X. Wang, H. Naohara, N. Marinkovic, K. More, H. Inada, et al., Recent advances in platinum monolayer electrocatalysts for oxygen reduction 
reaction: Scale-up synthesis, structure and activity of Pt shells on Pd cores, Electrochim. Acta. 55 (2010) 2645-2652. doi:10.1016/j.electacta.2009.11.106.

[10] K. Gong, D. Su, R.R. Adzic, Platinum-monolayer shell on AuNi(0.5)Fe nanoparticle core electrocatalyst with high activity and stability for the oxygen reduction reaction., J. Am. Chem. Soc. 132 (2010) 14364-6. doi:10.1021/ja1063873.

[11] D. V. Esposito, J.G. Chen, Monolayer platinum supported on tungsten carbides as low-cost electrocatalysts: opportunities and limitations, Energy Environ. Sci. 4 (2011) 3900-3912. doi:10.1039/c1ee01851e.

[12] D. V Esposito, S.T. Hunt, Y.C. Kimmel, J.G. Chen, A new class of electrocatalysts for hydrogen production from water electrolysis: metal monolayers supported on low-cost transition metal carbides., J. Am. Chem. Soc. 134 (2012) 3025-33. doi:10.1021/ja208656v.

[13] D. V Esposito, S.T. Hunt, A.L. Stottlemyer, K.D. Dobson, B.E. McCandless, R.W. Birkmire, et al., Low-cost hydrogen-evolution catalysts based on monolayer platinum on tungsten monocarbide substrates., Angew. Chem. Int. Ed. Engl. 49 (2010) 9859-62. doi:10.1002/anie.201004718.

[14] Y. Wang, K. Jiang, W.-B. Cai, Enhanced Electrocatalysis of Ethanol on Dealloyed Pd-Ni-P Film in Alkaline Media: an Infrared Spectroelectrochemical Investigation, Electrochim. Acta. 162 (2015) 100-107. doi:10.1016/j.electacta.2014.11.182.

[15] H. Wang, K. Jiang, Q. Chen, Z. Xie, W.-B. Cai, Carbon monoxide mediated chemical deposition of $\mathrm{Pt}$ or $\mathrm{Pd}$ quasi-monolayer on Au surfaces with superior electrocatalysis for ethanol oxidation in alkaline media, Chem. Commun. (2015). doi:10.1039/C5CC06551H.

[16] W. Sheng, H.A. Gasteiger, Y. Shao-Horn, Hydrogen Oxidation and Evolution Reaction Kinetics on Platinum: Acid vs Alkaline Electrolytes, J. Electrochem. Soc. 157 (2010) B1529-B1536.

[17] R.R. Adzic, J. Zhang, K. Sasaki, M.B. Vukmirovic, M. Shao, J.X. Wang, et al., Platinum Monolayer Fuel Cell Electrocatalysts, Top. Catal. 46 (2007) 249-262. doi:10.1007/s11244-007-9003-X.

[18] M. Shao, A. Peles, K. Shoemaker, M. Gummalla, P.N. Njoki, J. Luo, et al., Enhanced Oxygen Reduction Activity of Platinum Monolayer on Gold Nanoparticles, J. Phys. Chem. Lett. 2 (2011) 67-72. doi:10.1021/jz1015789.

[19] M.H. Shao, J. Warren, N.S. Marinkovic, P.W. Faguy, R.R. Adzic, In situ ATRSEIRAS study of electrooxidation of dimethyl ether on a Pt electrode in acid 
solutions, Electrochem. Commun. 7 (2005) 459-465.

doi:10.1016/j.elecom.2005.02.024.

[20] E.G. Mahoney, W. Sheng, Y. Yan, J.G. Chen, Platinum-Modified Gold Electrocatalysts for the Hydrogen Oxidation Reaction in Alkaline Electrolytes, ChemElectroChem. 1 (2014) 2058-2063.

[21] A. Hamelin, M.J. Sottomayor, F. Silva, S. Chang, M.J. Weaver, Cyclic voltammetric characterization of oriented monocrystalline gold surfaces in aqueous alkaline solution, J. Electroanal. Chem. 295 (1990) 291-300.

[22] A. Hamelin, Cyclic voltammetry at gold single-crystal surfaces. Part 1. Behaviour at low-index faces, J. Electroanal. Chem. 407 (1996) 1-11.

[23] N.M. Markovic, S.T. Sarraf, H.A. Gasteigert, P.N. Ross, Hydrogen electrochemistry on platinum low-index single-crystal surfaces in alkaline solution, J. Chem. Soc. 92 (1996) 3719-3725.

[24] K. Sasaki, Y. Mo, J.X. Wang, M. Balasubramanian, F. Uribe, J. McBreen, et al., Pt submonolayers on metal nanoparticles-novel electrocatalysts for $\mathrm{H} 2$ oxidation and $\mathrm{O} 2$ reduction, Electrochim. Acta. 48 (2003) 3841-3849. doi:10.1016/S00134686(03)00518-8.

[25] S. Trasatti, O.A. Petrii, Real surface area measurements in electrochemistry, J. Electroanal. Chem. 327 (1992) 353-376.

[26] A. Michri, A. Pshchenichikov, R. Burshtein, Determining the actual surface area of smooth gold electrodes, Elektrokhimiya. 8 (1972) 351.

[27] H. Angerstein-Kozlowska, B.E. Conway, A. Hamelin, L. Stoicoviciu, Elementary steps of electrochemical oxidation of single-crystal planes of Au. Part II. A chemical and structural basis of oxidation of the (111) plane, J. Electroanal. Chem. 228 (1987) 429-453.

[28] R. Holze, Electrocatalytic oxidation of mono- and polyhydric alcohols on gold and platinum, 27 (1997) 999-1011.

[29] B.N. Zope, D.D. Hibbitts, M. Neurock, R.J. Davis, Reactivity of the gold/water interface during selective oxidation catalysis., Science. 330 (2010) 74-8. doi:10.1126/science.1195055.

[30] Y. Kwon, S.C.S. Lai, P. Rodriguez, M.T.M. Koper, Electrocatalytic Oxidation of Alcohols on Gold in Alkaline Media : Base or Gold Catalysis?, J. Am. Chem. Soc. 133 (2011) 6914-6917. 
[31] R.E. Rettew, S. Cheng, M. Sauerbrey, T. a. Manz, D.S. Sholl, C. Jaye, et al., Near Surface Phase Transition of Solute Derived Pt Monolayers, Top. Catal. 56 (2013) 1065-1073. doi:10.1007/s11244-013-0071-9.

[32] S.C. Chang, Y. Ho, M.J. Weaver, Applications of real-time FTIR spectroscopy to the elucidation of complex electroorganic pathways: electrooxidation of ethylene glycol on gold, platinum, and nickel in alkaline solution, J. Am. Chem. Soc. 113 (1991) 9506-9513. doi:10.1021/ja00025a014.

[33] F. Kadirgan, C. Lamy, J.M. Lkger, B. Beden, Mechanistic study of the electrooxidation of ethylene glycol on gold and adatom-modified gold electrodes in alkaline medium, J. Electroanal. Chem. 286 (1990) 41-61.

[34] M. Pasta, F. La Mantia, Y. Cui, Mechanism of glucose electrochemical oxidation on gold surface, Electrochim. Acta. 55 (2010) 5561-5568. doi:10.1016/j.electacta.2010.04.069.

[35] R.R. Adzic, M.W. Hsiao, E.B. Yeager, Electrochemical oxidation of glucose on single crystal gold surfaces, J. Electroanal. Chem. 260 (1989) 475-485.

[36] K. Kokoh, J.-M. Leger, B. Beden, H. Huser, C. Lamy, "On line" chromatographic analysis of the products resulting from the electrocatalytic oxidation of D-glucose on pure and adatoms modified Pt and Au electrodes - Part II: Alkaline medium, Electrochim. Acta. 37 (1992) 1909-1918.

[37] I.T. Bae, E. Yeager, X. Xing, C.C. Liu, In situ infrared studies of glucose oxidation on platinum in an alkaline medium, J. Electroanal. Chem. Interfacial Electrochem. 309 (1991) 131-145. doi:10.1016/0022-0728(91)87009-S.

[38] L.H. Essis Yei, B. Beden, C. Lamy, Electrocatalytic Oxidation of Glucose at Platinum in Alkaline Medium: On the Role of Temeprature, J. Electroanal. Chem. 246 (1988) 349-362.

[39] M.F.L. de Mele, H.A. Videla, A.J. Arvia, The Electrooxidation of Glucose on Platinum Electrodes in Buffered Media, Bioelectrochemistry Bioenerg. 10 (1983) 239-249.

[40] Y.B. Vassilyev, O.A. Khazova, N.N. Nikolaeva, Kinetics and mechanism of glucose electrooxidation on different electrode-catalysts: Part I. Adsorption and oxidation on platinum, J. Electroanal. Chem. 196 (1985) 105-125.

[41] K.D. Popovic, N.M. Markovic, A. V Tripkovic, R.R. Adzic, Oxidation of D-glucose on single crystal platinum electrodes in alkaline solution, J. Electroanal. Chem. 313 (1991) 181-199. 
[42] B. Beden, F. Largeaud, K.B. Kokoh, C. Lamy, Fourier transform infrared reflectance spectroscopic investigation of the electrocatalytic oxidation of Dglucose: Indentification of reactive intermediates and reaction products, Electrochi. 41 (1996) 701-709. 
Figure list.

Figure 1:
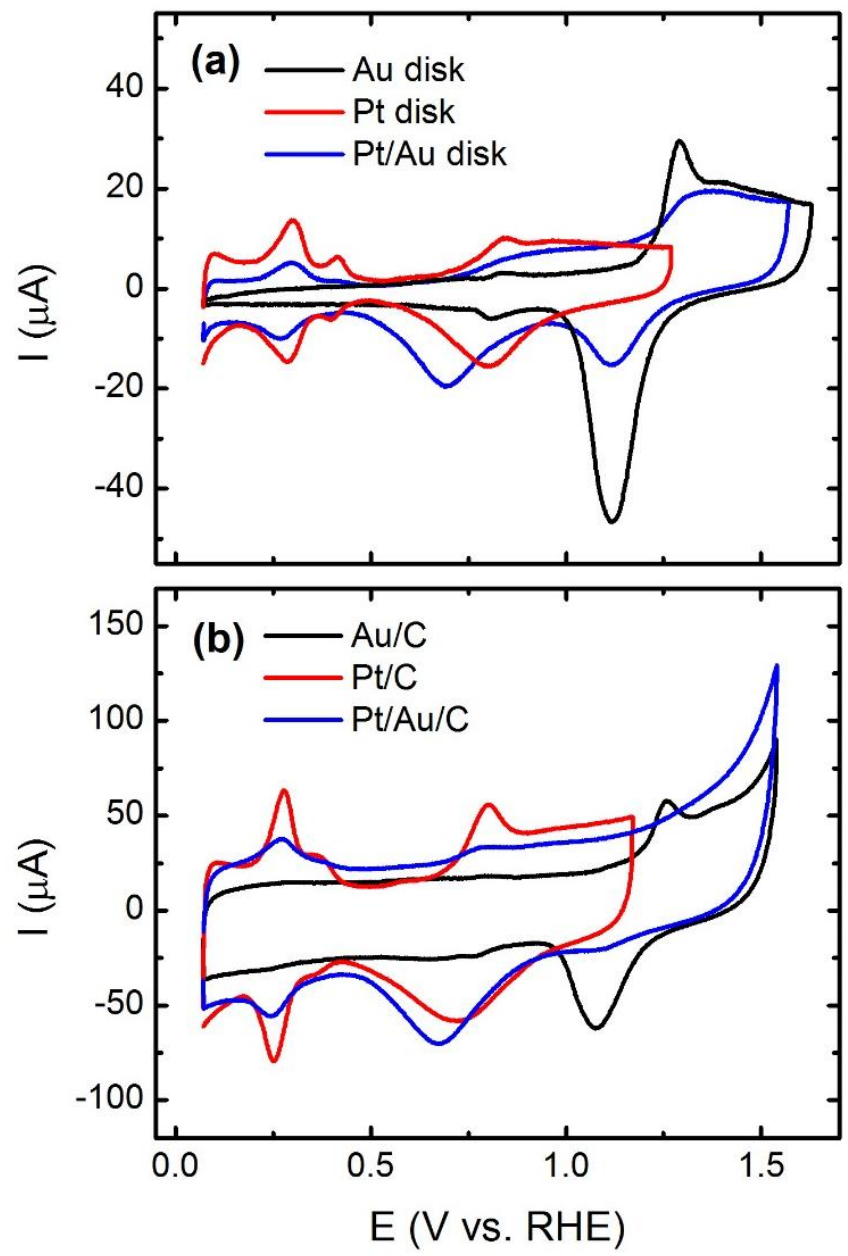
Figure 2:
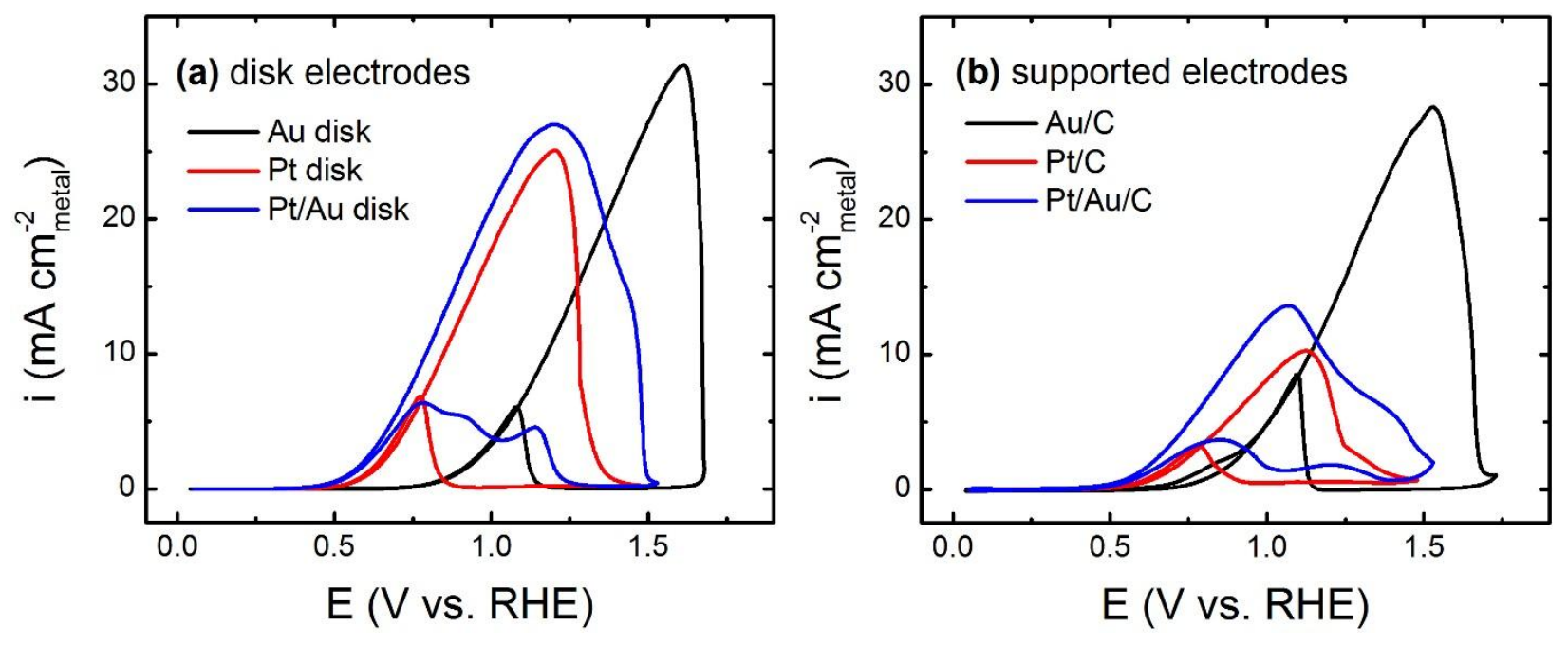

Figure 3:

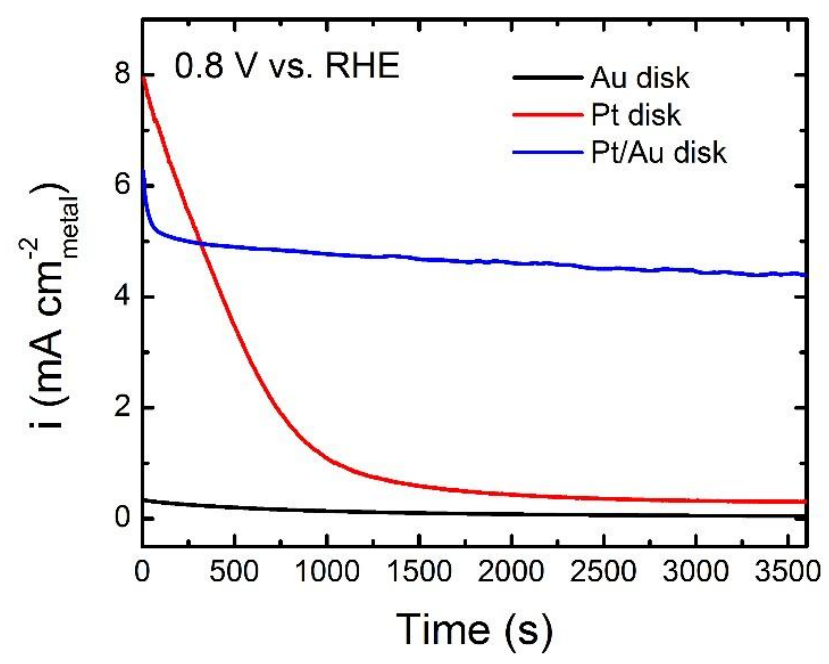


Figure 4:

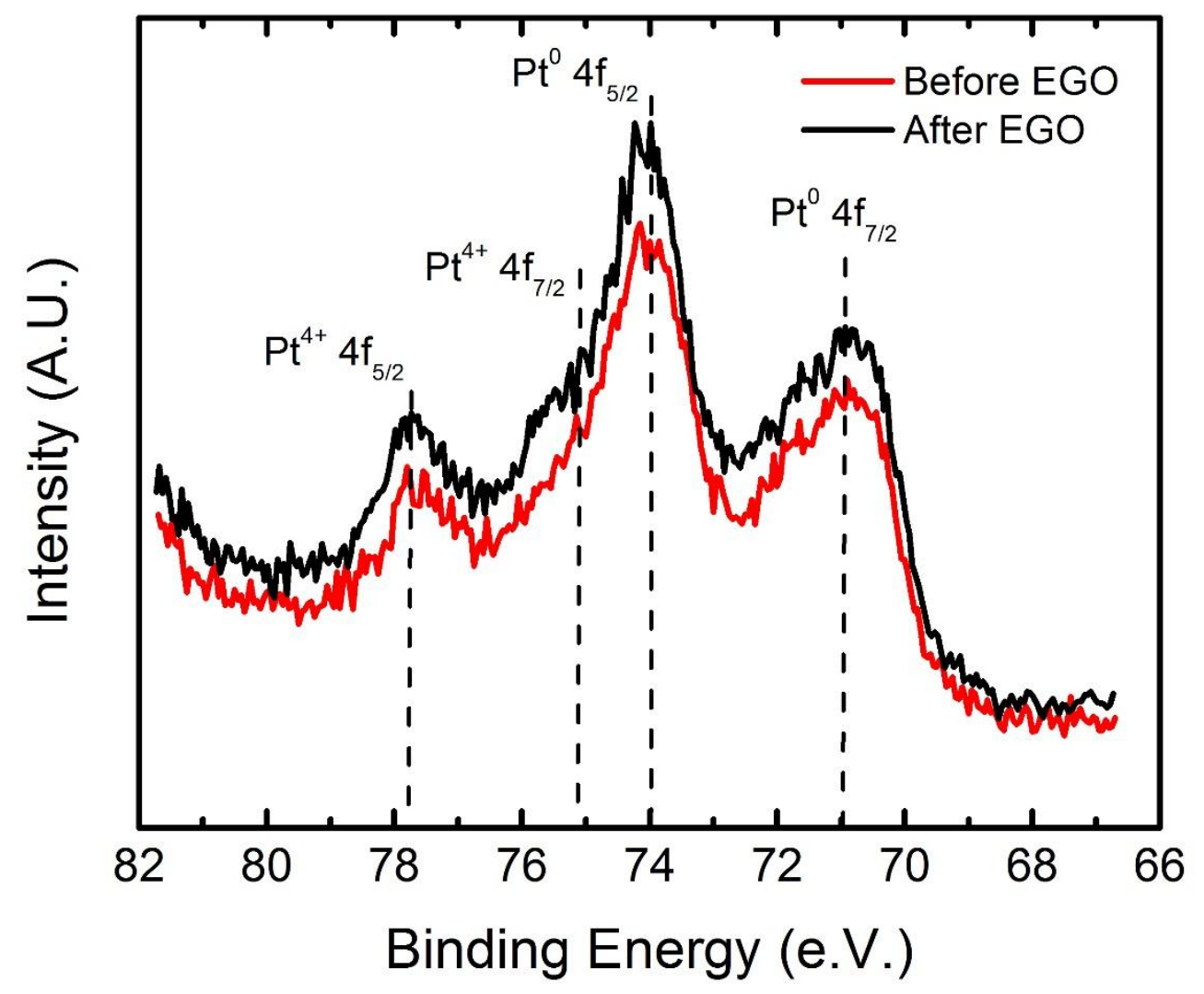


Figure 5:

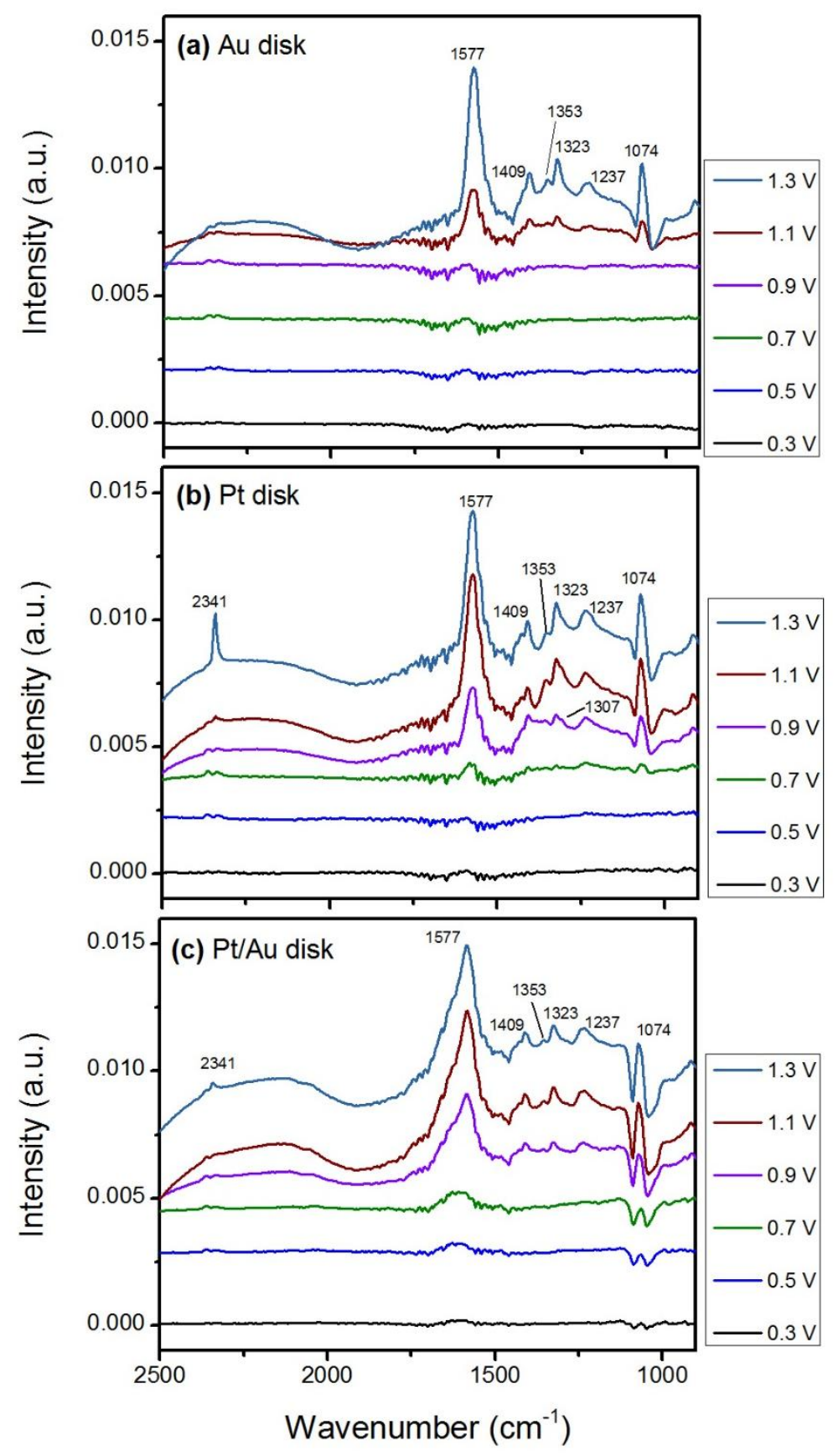


Figure 6:
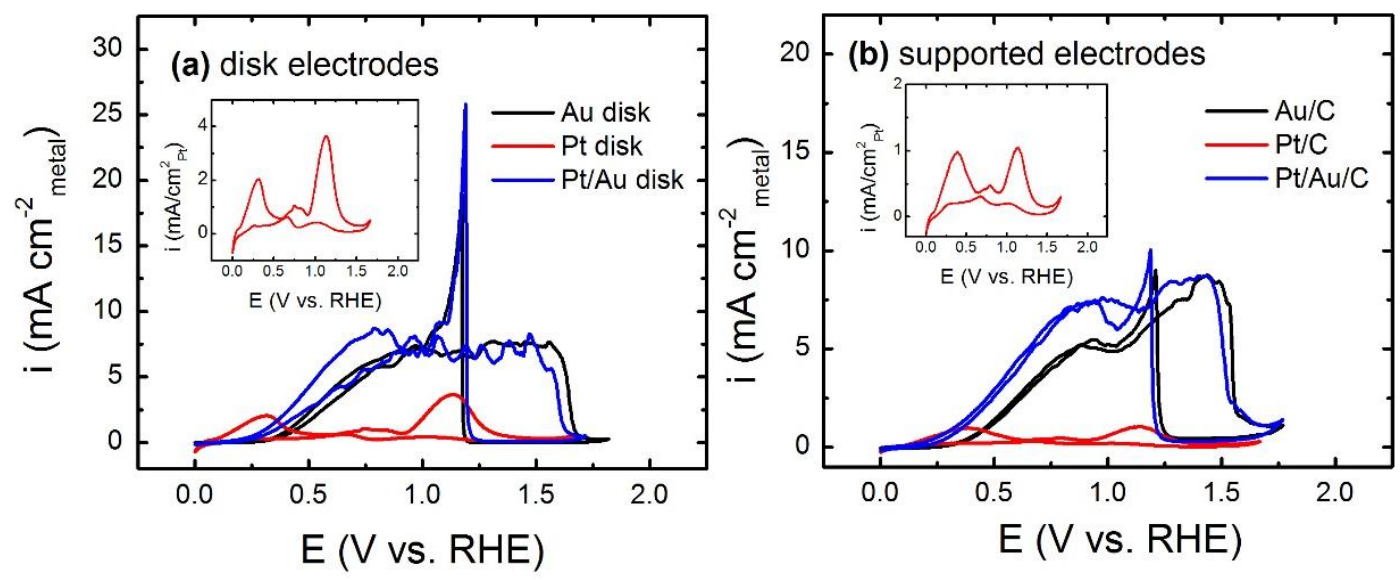

Figure 7:

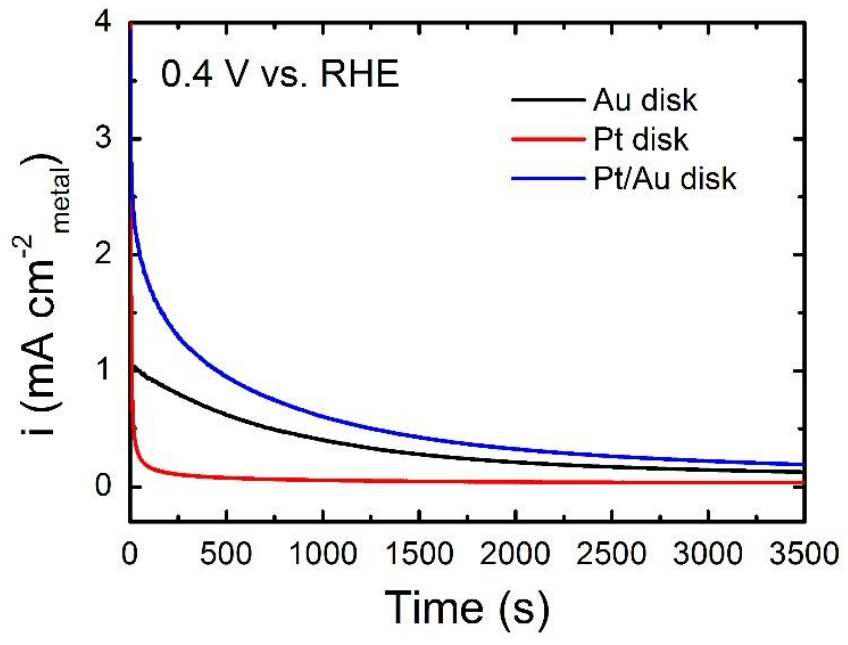


Figure 8:

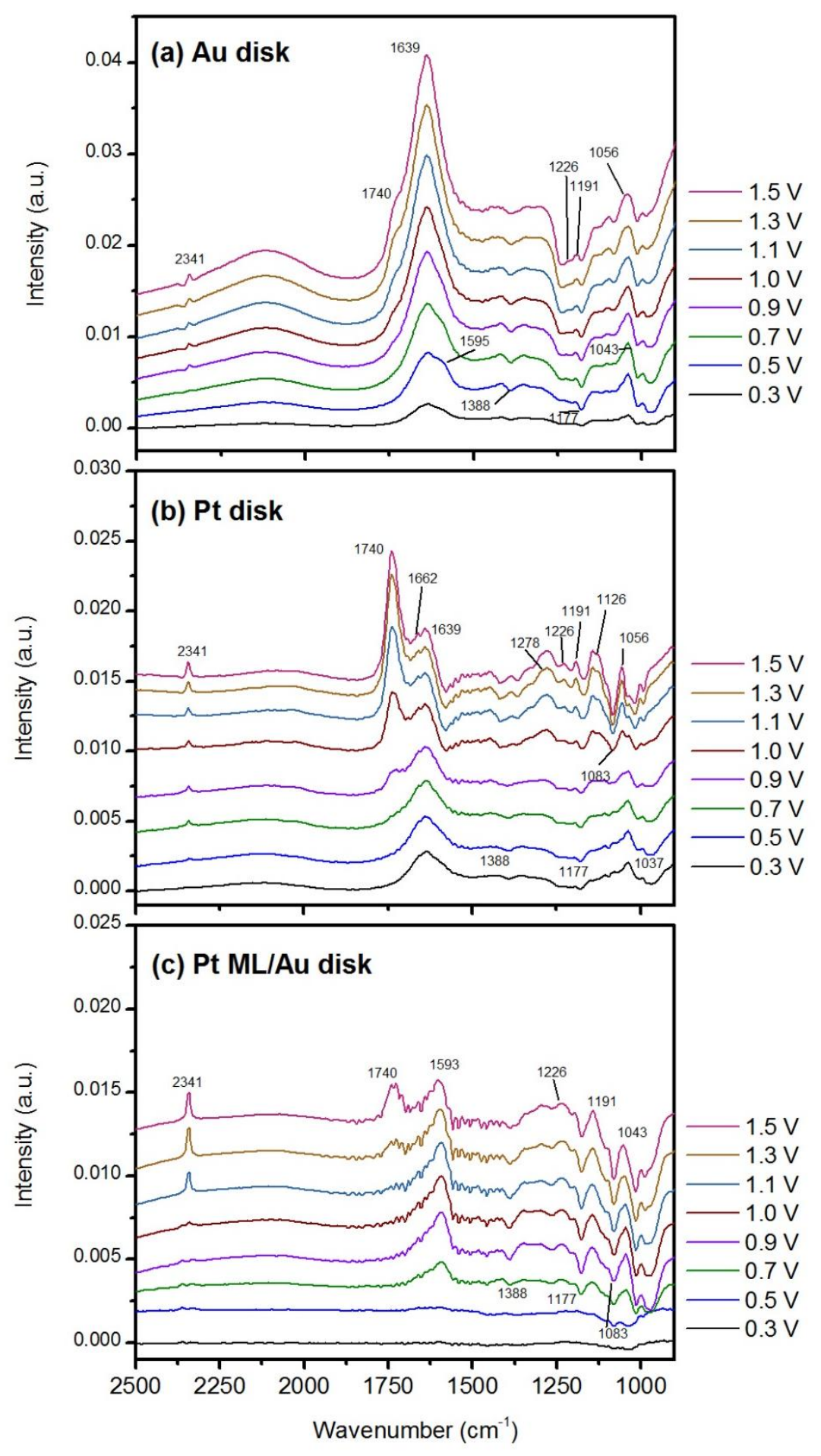




\section{Table 1}

\begin{tabular}{lll}
\hline Electrode & $\begin{array}{l}\text { Roughness Factor } \\
\left(\mathrm{cm}^{2}{ }_{\text {metal }} \mathrm{Cm}^{-2}{ }_{\text {disk }}\right)\end{array}$ & $\begin{array}{l}\text { Specific Area } \\
\left(\mathrm{m}^{2} \mathrm{~g}^{-1} \text { metal }\right)\end{array}$ \\
\hline Au disk & $1.18 \pm 0.02$ & -- \\
$\mathrm{Pt}$ disk & $1.2 \pm 0.1$ & -- \\
$\mathrm{Pt} / \mathrm{Au}$ disk & $1.2 \pm 0.2$ & -- \\
$\mathrm{Au} / \mathrm{C}$ & $1.9 \pm 0.1$ & $5.8 \pm 0.3$ \\
$\mathrm{Pt} / \mathrm{C}$ & $3.5 \pm 0.3$ & $50 \pm 4$ \\
$\mathrm{Pt} / \mathrm{Au} / \mathrm{C}$ & $1.8 \pm 0.1$ & $5.5 \pm 0.3^{\mathrm{a}}$ \\
\hline
\end{tabular}

${ }^{\mathrm{a}}$ Normalized by the total mass of Pt and $\mathrm{Au}$ 
Table 2

Wavenumber $\left(\mathrm{cm}^{-1}\right) \quad$ Assignment

1074

Aldehyde stretch in glyoxal and glycolate[26-28]

1237

C-O stretch of glycolate[27,29]

1323

Symmetric $\mathrm{COO}^{-}$stretch of glycolate, glyoxal, and oxalate[27,29]

1353

1409

Symmetric $\mathrm{COO}^{-}$stretch in formate[26,28,30]

Adsorbed carbonylate[27,29]

Symmetric $\mathrm{COO}^{-}$stretch in glycolate[26,28]

Carbonate $\left(\mathrm{CO}_{3}^{-2}\right)[27,31]$

1577

Asymmetric $\mathrm{COO}^{-}$stretch in glyoxal and glycolate[26-29]

2341

Asymmetric $\mathrm{CO}_{2}$ stretch[26-29] 
Table 3

\begin{tabular}{ll}
\hline Wavenumber $\left(\mathrm{cm}^{-1}\right)$ & Assignment \\
\hline 1043 & $\mathrm{~V}(\mathrm{C}-\mathrm{O})$ in $\mathrm{CH}_{2} \mathrm{OH}$ in gluconate[40] \\
1098 & $\mathrm{~V}(\mathrm{C}-\mathrm{O})$ in $\mathrm{CH}_{2} \mathrm{OH}$ in gluconate[40] from $\mathrm{CHOH}$ in $\delta$-gluconolactone[40] \\
1126 & Unknown peak in $\delta$-gluconolactone[40] \\
1191 & $\mathrm{CH}$ wag in $\delta$-gluconolactone[40] \\
1226 & $\mathrm{~V}(\mathrm{C}-\mathrm{O})$ from $\mathrm{CH}_{2} \mathrm{OH}$ in glucose[40] \\
1177 (negative) & $\mathrm{C}-\mathrm{H}$ bending in glucose[35,40] \\
1388 (negative) & Asymmetric stretch of O - C - O in gluconate[35,40] \\
1593 & $\mathrm{C}=\mathrm{O}$ of ring-opened glucose \\
1639 & $\mathrm{~V}(\mathrm{C}=\mathrm{O})$ of $\delta$-gluconolactone[35,40] \\
& Asymmetric $\mathrm{CO}_{2}$ stretch[35,40] \\
\hline
\end{tabular}

